This is the accepted version of the manuscript published by Wiley in British Journal of Social Psychology, doi: 10.1111/bjso.12132

Boag, E. M., \& Carnelley, K. B. (2016). Attachment and prejudice: The mediating role of empathy. British Journal of Social Psychology, 55, 337-356.

Correspondence should be addressed to Elle M. Boag, Department of Psychology, School of Social Sciences, Birmingham City University, 4, Curzon

St, Birmingham B4 7BD, UK (email: elle.boag@bcu.ac.uk).

Attachment and prejudice: The mediating role ofempathy

\begin{abstract}
In two studies, we examined the novel hypothesis that empathy is a mechanism through which the relationship between attachment patterns and prejudice can be explained. Study 1 examined primed attachment security (vs. neutral prime), empathy, and prejudice towards immigrants. Study 2 examined primed attachment patterns (secure, avoidant, anxious), empathy subscales (perspective taking, empathic concern, personal distress), and prejudice towards Muslims. Across both studies, empathy mediated the relationship between primed attachment security and low prejudice levels. The findings suggest that enhancing felt security and empathic skills in individuals high in attachment-avoidance may lead to reduced prejudice.
\end{abstract}


Social psychologists have begun to integrate literatures on intergroup and interpersonalrelations using attachment theory showing that those high (vs. low) in attachmentsecurity are less prejudiced (Hofstra, van Oudenhoven, \& Buunk, 2005; Mikulincer \& Shaver, 2001; van Oudenhoven \& Hofstra, 2006). However, if we are to fully understandthe reasons why variations in attachment patterns are associated with variations inprejudice, we must examine possible mechanisms underlying these relations. Thisresearch avenue has been empirically neglected, an issue we address in two studiesexamining whether the link between attachment patterns and prejudice can be explainedby the mechanism of empathy.

\section{Attachment and prejudice}

Attachment theory (Bowlby, 1969) explains how interactions with primary caregivers influence the development of internal working models of self, others and the world that underlie individual differences in attachment patterns. Individuals who receive sensitive and reliable care from attachment figures in times of need develop positive models of the self, others and the world. These working models may influence attitudes towards outgroups.

Two dimensions underlie attachment patterns: Attachment anxiety (fear of abandon- ment) and avoidance (discomfort with closeness). Attachment patterns tend towards stability (Hamilton, 2000) but are open to revision based on new experiences with attachment figures. Furthermore, they can be dispositional (chronic) or relationship-specific, and can be temporarily induced via priming (Baldwin, Keelan, Fehr, Enns, \& Koh-Rangarajoo, 1996). Baldwin et al. (1996) found that adults typically have relation- ship-specific models of each attachment style. So, although a person may be disposition-ally avoidant, he/she may have specific relationships that make him/her feel secure oranxious. Baldwin et al. found that people hold more relationship-specific models congruent with their chronic attachment style compared to people with a different attachment style; for example, people who are dispositionally secure have morerelationships that are secure than do people who are dispositionally avoidant or anxious.Furthermore, contextually activating (priming) a sense of security (state security) bywriting about an attachment figure who makes one feel secure, for example, leads peopleto respond in a similar manner to people who have a secure attachment pattern (dispositional security; Rowe \& Carnelley, 2003). When we activate in mind a given attachment model, thoughts and feelings linked to that model will also be activated, via theprocess of spreading activation to other schemas. So, if one is dispositionally avoidant buthas been primed with a secure model, one will show more sensitive caregiving and moreempathy to others (albeit temporarily) due to spreading activation (Mikulincer et al.,2001; Mikulincer, Shaver, Sahdra, \& Bar-On, 2013). Attachment models are thought to be organized hierarchically with chronically activated models at the top and relationship-specific models at the bottom (Collins \& Read, 1994). Both top down (chronic torelationship-specific) and bottom up (relationship-specific to chronic) informationprocessing can occur.

Bowlby (1969) specified that a core issue in attachment theory is the regulation of negative emotions provoked by situations or people perceived as threatening or dangerous. On perceiving threat, the primary attachment strategy (Main, 1990) is to seekproximity (actual or imagined) to the attachment figure; proximity, in turn, diminishesnegative emotions by creating 'felt security' (Sroufe \& Waters, 1977). Following felt security, the attachment behavioural system is deactivated and the individual can engagein other behaviours, such as exploration (Ainsworth, Blehar, Waters, \& Wall, 1978). Secure individuals have positive models of self and others (Bartholomew \& Horowitz, 1991), are typically high in social competence (Zimmerman, 2004), are open to experiences (Noftle \& Shaver, 2006), and show favourable views towards humanity(Luke, Maio, \& Carnelley, 2004), all of which may lead to less prejudiced behaviour, and more engagement with outgroup members. 
When an attachment figure is not responsive or available, secondary strategies of affect regulation ensue. If proximity-seeking is a viable option then the attachment system ishyperactivated leading to behaviours aimed at increasing proximity; this is the attachment-anxious strategy. Those high in attachment anxiety are hypervigilant tothreat and have more aversive social and relationship goals (Carnelley \& Story, 2008; Gable, 2006). This hypervigilance may extend to the wider environment and includeattention to outgroup sources of threat. In addition they have low humanity-esteem (Lukeet al., 2004) and are more likely to make stereotype-based judgments (Mikulincer, 1997). All of these might lead them to be prejudiced towards outgroup members.

If proximity is not a viable option, the attachment system is chronically deactivated. This is characteristic of those high in attachment avoidance, who increase distance fromothers and compulsively rely on the self. Avoidant attachment is associated with negativemodels of others (Bartholomew \& Horowitz, 1991), low appetitive relationship goals(Carnelley \& Story, 2008), low approach motivation (Meyer, Olivier, \& Roth, 2005), low agreeableness (Mikulincer \& Shaver, 2007), low humanity-esteem (Luke et al., 2004), and more use of stereotype-based judgments (Mikulincer, 1997). Therefore, avoidance may beassociated with prejudice as a means of distancing oneself from others.

Prejudice is an affective response (Cotterell \& Neuberg, 2005) towards individuals or groups who are different from oneself or familiar others and is associated with 'feelings of scorn or dislike, of fear or aversion' (Allport, 1954/1979, p. 7). Research has linked both attachment avoidance and attachment anxiety with negative attitudes towards immi- grants' adaptation strategies (Hofstra et al., 2005; van Oudenhoven \& Hofstra, 2006), established correlates of prejudice and racism (Zick, Keipper, \& H6vermann, 2011). Secure adults had positive attitudes towards immigrants' integration, while dismissing- and fearful-avoidant adults had negative attitudes towards integration. Dismissing individuals endorsed a preference that immigrants maintain separation from the host society. People with high attachment anxiety endorsed attitudes that immigrants should be marginalized. In addition, Di Pentima and Toni (2009) found that high attachment avoidance predicted the highest levels, and attachment security the lowest levels, of blatant and subtle prejudice towards outgroup members. Attachment anxiety predicted high subtle prejudice and low blatant prejudice, but both scores sat between those of attachment avoidance and security. Moreover, Mikulincer and Shaver (2001) demon- strated that priming attachment security reduced negative evaluations of outgroups known to elicit feelings of hostility, anxiety, and fear in an Israeli-Jewish population.

Research examining why secure attachment is associated with low prejudice is limited. Empathy is a mechanism that might explain this link. If social psychology is to continue to make useful contributions to prejudice reduction techniques, we need to identify psychological mechanisms that might be manipulated in interventions.

\section{Empathy and prejudice}

Empathy is the spontaneous ability to take the perspective of, and understand the feelings of another person, and the ability to use emotional responses appropriate to one's emotional state (Baron-Cohen \& Wheelwright, 2004). Batson and Ahmad (2009), in a review of prejudice reduction techniques, state that empathy 'has the potential to improve intergroup relations' (p. 142). We examine whether empathy might explain the relation between attachment patterns and prejudice.

Allport (1954/1979) proposed that people high in empathy are more tolerant of others. Since Allport's insightful comments, the connection between high dispositional empathy and low prejudice has emerged as robust and stable (B€ackstro€m \& Bjo€rkund, 2007; Pederson, Beven, Walker, \& Griffiths, 2004). Additionally, empathy consistently mediates the link between intergroup contact and prejudice (see meta-analysis byPettigrew \& Tropp, 2008). Furthermore, research shows that experimentally enhancedempathy (via perspective taking instructions) decreases prejudice (Batson, Chang, Orr, \&Rowland, 2002; Batson et al., 1997; Finlay \& Stephan, 2000; Galinsky \& Moskowitz, 2000). We examine the novel 
hypothesis that empathy is a mediator of the link betweenattachment patterns and prejudice.

\section{Attachment and empathy}

People with different attachment patterns should differ in empathy levels due to the nature of care received from attachment figures. One developmental milestone shown to relate to attachment security and empathy is theory of mind (Fonagy, Redfern, \& Charman, 1997; Meins, Fernyhough, Russell, \& Clark-Carter, 1998), which is the ability to understand that others have different beliefs, desires, and intentions than oneself (Baron-Cohen, 2001). Meins et al. (1998) showed that the parents of securely attached infants are mind-minded that is, infants are treated as individuals with goals and desires of their own. Furthermore, parental mind-mindedness led to the child developing an earlier understanding of mentalstates and the acquisition of theory of mind. Fonagy et al. (1995) maintain that a caregiver's ability to evaluate and comprehend not just the intentions behind the behaviours of theiroffspring, but also the feelings and needs behind those behaviours (reflective functioning)is crucial in developing attachment security. This suggests that the use of reflective functioning within caregiving practices directly exposes children to empathic behaviours; thus reflective functioning facilitates the development of empathic skills.

Consistent with the above theoretical links, research shows that attachment patterns are associated with empathy. Dispositional and primed attachment security are associated withhighempathy andaltruistic compassion(Mikulincer et al.,2001; Mikulincer, Shaver, Gillath, \& Nitzberg, 2005;). Avoidantly attached people are relatively low in empathy (Mikulincer et al., 2001; Rowe \& Mohr, 2007) and lack compassion because egoistic motives leave them uninterested in others' point of view (Mikulincer et al., 2005). We might expect those high in attachment anxiety to be motivated to be empathic but have difficulties perspective taking due to their internalized models of intrusive and overprotective care. Their focus on getting their own attachment needs met may interfere with their ability to turn away from the self and accurately perceive others. For example, Feeney and Collins (2001) found that highly anxious caregivers have difficulty determining when a partner needs care; they provide high emotional support, regardless of their partner's distress level. Furthermore, regardless of their partners' distress levels, anxious caregivers focused on and were distracted by thoughts of their partner and demonstrated high emotional empathy towards their partner (Collins, Ford, Guichard, Kane, \& Feeney, 2009). Others have found no association between attachment anxiety and empathy (Rowe \& Mohr, 2007; Wayment, 2006). Taken together, we expect secure attachment to be positively linked with empathy, avoidance to be negatively linked with empathy, and make no prediction for attachment anxiety.

\section{Currentresearch}

Thus far the relations between attachment, prejudice and empathy have been examinedseparately. Our novel research aimed to demonstrate that empathy explains the relationbetween attachment and prejudice. Study 1 examined the causal effects of primingattachment security (vs. a neutral prime) on empathy and prejudice. We expected primedsecurity to have the same effect on empathy and prejudice as dispositional security; weexpected primed security to lead to low prejudice due to high empathy. Study 2 examinedthe causal effects of priming attachment styles (security, avoidance, and anxiety) onempathy and prejudice. Again, we expected primed style to show similar results asdispositional attachment style and expected empathy to mediate between attachment and prejudice. Outgroup choices were varied to increase generalizability. In Study 1 the targetgroup was immigrants and in Study 2 it was Muslims.

\section{STUDY 1}

\section{Hypotheses}

We expected to replicate research demonstrating that people primed with attachment security (vs. neutral prime) report lower prejudice (Mikulincer \& Shaver, 2001) towards immigrants (Hypothesis 1) and higher empathy (Mikulincer et al., 
2001; Hypothesis 2). Hypothesis 3 examined the novel prediction that the lower prejudice reported by people primed with attachment security (vs. neutral prime) would be explained by increased empathy (i.e., empathy should mediate the link between prime and prejudice).

\section{Method}

\section{Participants}

The sample was based on 124 volunteers $\left(87.1 \%\right.$ students; $76.6 \%$ female; $M_{\text {age }}=24.0$, $S D=8.13 ; 18$ immigrants were excluded) recruited from websites used for social- psychological research. ${ }^{1}$ The majority were White $(79.0 \%)$; the remainder were $10.5 \%$ Black, $4.8 \%$ Latino/a, $1.6 \%$ Asian. Participants were mostly from the USA $(83.9 \%)$; the rest were from Canada $(4.8 \%)$ and the UK $(4.0 \%)$.

\section{Priming manipulation}

\section{Secure prime}

We primed attachment security using a visualization and writing task (adapted from Rowe

\& Carnelley, 2003) instructing participants to think about a close relationship indicative ofattachment security (emotional closeness, comfort in dependency on partner, no fear ofabandonment), and write about it for $8 \mathrm{~min}^{2}$ Participants wrote about a: Romanticpartner $(56.3 \%)$, friend/best friend (39.1\%), mother (1.6\%), ex-romantic partner (1.6\%), and AA sponsor (1.6\%).

\section{Neutral relationship prime}

Neutral primed (adapted from Kumashiro \& Sedikides, 2005) participants visualized andwrote about a neutral relationship (someone they neither liked nor disliked; someone theydid not know very well) for $8 \mathrm{~min}$. Participants wrote about a: Colleague/classmate( $43.3 \%)$ or acquaintance $(56.6 \%)$.

\section{Measures}

Felt security

As a manipulation check, felt security was assessed using a 10 -item $(\mathrm{a}=.96)$ measure (Luke, Sedikides, \& Carnelley, 2012). Participants rated agreement on a 6-point scale ranging from 1 (not at all) to6 (very much). Items (comforted, secure, supported, safe,loved, protected, better about myself, encouraged, sheltered, unthreatened) were

preceded by: 'Thinking about what I described in the visualization task makes me feel. ...

\section{Empathy}

State empathy was assessed using Batson's (1991) 6-item measure $(\mathrm{a}=.91)$. Participants rated agreement on a 5-point scale ranging from 1 (not at all) to 5 (extremely).

Items (sympathetic, moved, compassionate, tender, warm, and soft-hearted) were preceded by: 'Thinking about what I described in the visualisation task makes me feel. .

\section{Prejudice}

Akrami, Ekehammar, and Araya's (2000) Modern Racial Prejudice Scale (MRPS) was modified to reflect non-specific national identification (opposed to Swedish refer-ences) to measure explicit prejudice. Three items tap denial of continuing discrimination (Discrimination against immigrants is no longer a problem in my country'), three tap antagonism towards demands ('Immigrants are getting too demanding in the push for equal rights'), and three tap resentment about special favours (There have been enough programs designed to create jobs for immigrants'). Participants were told: Thinking about what you described in the visualisation task, rate the following statement: on a 5-point scale ranging from 1 (not at all) to 5 (extremely); high scores reflect high prejudice. Reliability was adequate $(\mathrm{a}=.74$, nine items including five tapping positive attitudes), consistent with previous research 
(Akrami et al., 2000).

\section{Procedure}

Participants completed materials online and were randomly assigned to either the secure attachment prime or neutral relationship prime condition. Participants provided informed consent, conducted the visualization task, and completed felt security, empathy, and prejudice measures (in this order) and were debriefed.

\section{Results}

\section{Effectsofprime}

Table 1 shows that participants in the secure prime condition reported higher felt security than participants in the neutral prime condition, indicating the success of the prime manipulation. Importantly, compared to the neutral condition, secure priming increased reports of empathy and decreased reports of prejudice towards immigrants, consistent with Hypotheses 1 and 2.

Table 1. Descriptive statistics for dependent variables by prime (Study I)

\begin{tabular}{|c|c|c|c|c|c|}
\hline \multicolumn{6}{|c|}{ Prime condition } \\
\hline & \multicolumn{2}{|c|}{ Secure } & \multicolumn{2}{|c|}{ Neutral } & \\
\hline & M & $S D$ & M & $S D F$ & \\
\hline Felt security & $4.70_{a}$ & 1.06 & $2.72_{b}$ & 1.18 & $97.12^{* *}$ \\
\hline Empathy & $3.74_{a}$ & 0.95 & $2.39_{b}$ & 0.95 & $62.73 * *$ \\
\hline Prejudice & $2.74_{a}$ & 0.70 & $2.98_{b}$ & 0.60 & $4.19 *$ \\
\hline
\end{tabular}

Note. Row means with different subscripts are significantly different from one another at the $p<.05$ level (Secure prime $N=64$, Neutral prime $N=60$ ).

$* * p<.01 ; * p<.05$. 


\section{Correlation and mediation analysis}

Empathy negatively correlated with prejudice, $r=-.27, p<.01 .^{3}$ (Felt security correlated $-.21, p=.018$ with prejudice, and $.79, p<.001$ with empathy.) We conducted a hierarchical regression to determine whether empathy mediated the relationship between prime and prejudice. Prejudice was the criterion, with prime (Step

1) and empathy (Step 2) as predictors, overall $F(2,121)=4.91, p<.01$; cumulative $R^{2}=.08$. Prime significantly predicted prejudice at Step $1(B=-$ $0.24, p<.05)$, and when empathy $(B=-0.14, p<.02)$ was added to the equation (Step 2) prime no longer significantly predicted prejudice $(B=-0.05, n s)$, indicating mediation was likely.

We used bootstrapping (Preacher \& Hayes, 2004) to test mediation. Supporting Hypothesis 3, the indirect effect of prime on prejudice via empathy was significant $(95 \% \mathrm{CI}=-0.40,-0.03, p<.05)$, indicating that empathy mediates the relationship between prime and prejudice. Priming attachment security (compared to a neutral relationship) leads to increased levels of empathy, which in turn lead to reduced levels of prejudice towards immigrants.

\section{STUDY 2}

We examined whether we could replicate the Study 1 finding that primed security leads to low prejudice due to high empathy, with a different target group (Muslims) in Study 2. In Study 2 we manipulated (primed) attachment anxiety. Furthermore, we primed avoidance to determine whether avoidance causes prejudice due to low empathic skills. In addition, we examined which aspects of empathy were the most important mediators of the link between attachment patterns and prejudice.

Empathy is a complex, multifaceted construct that involves both cognitive and emotional compo- nents (Davis, 1980). Perspective taking is the cognitive component. Emotional empathy (or empathic concern) involves feeling and responding with compassion towards a person in distress (Mehrabian \& Epstein, 1972); whereas personal distress involves discomfort and anxiety that is a selffocused response to witnessing the negative experiences of others (Batson et al., 1997). Research demonstrates that primed and dispositional attachment security are associated with better perspective taking and higher empathic concern (Joireman, Needham, \& Cummings, 2001; Rowe \& Mohr, 2007). Avoidantly attached people are low in empathic concern and perspective taking ability (Joireman et al., 2001). Findings for attachment anxiety are inconsistent. Although research shows no association between attachment anxiety and empathy when total scores are used (Rowe \& Mohr, 2007; Wayment, 2006), results for specific aspects of empathy differ. The most reliable finding is that attachment anxiety is associated with high personal distress (Britton \& Fuendeling, 2005; Joireman et al., 2001) and high emotional empathy (Trusty, Ng, \& Watts, 2005). Findings for perspective taking are mixed; Joireman et al. (2001) show a negative association and Britton and Fuendeling (2005) find a positive association between the two. Finally,

Britton and Fuendeling (2005) find attachment anxiety is linked to low empathic concern. Further research is required to clarify this discrepancy.

Batson, Eklund, Chermok, Hoyt, and Ortiz(2007) suggest that perspective taking is the keystone of empathic responding, a precursor to empathic concern. Therefore, we might 
expect perspective taking to explain the link between attachment security and prejudice. It might be necessary to take another's perspective in order to develop a positive attitude towards an outgroup member. Alternatively, empathic concern might be most important. Perhaps feeling compassion for another, regardless of whether or not one can see things from the other's perspective, is what is necessary to develop a positive attitude towards an outgroup member. Given that the personal distress aspect of empathy is self-focused, we did not expect personal distress to explain the link between attachment security and prejudice.

Identifying the specific aspects of empathy that mediate between attachment and prejudice has implications for interventions that use empathy induction to reduce prejudice (Batson \& Ahmad, 2009). Empathy inductions could be tailored to attachment patterns and focus on perspective taking instructions or on increasing empathic concern, depending on results.

We assessed allophilia in Study 2 to determine whether participants primed with attachment security would report low prejudice. To complement allophilia's focus on positive attitudes, we also assessed Social Dominance Orientation (SDO; Pratto, Sidanius, Stallworth, \& Malle, 1994), which although not a measure of prejudice consistently predicts prejudice (Pratto et al., 2000; Sidanius, Levin, Liu, \& Pratto, 2000; Sidanius \& Pratto, 1999). SDO is defined as a 'general individual difference orientation expressing the value that people place upon non-egalitarian and hierarchically structured relationships among social groups. It expresses general support for the domination of certain socially constructed groups over other socially constructed groups... (Sidanius \& Pratto, 1999, p. 61). Research indicates that attachment avoidance is associated with higher social dominance orientation (Weber \& Federico, 2007). To reduce the possibility of demand characteristics, we no longer asked participants to 'think back to the visualization task' when reporting on empathy and prejudice; we used a cover story to hide the purpose of the study.

\section{Hypotheses}

We hypothesized that perspective taking (Hypothesis 1) and empathic concern (Hypothesis 2) would be highest in people primed with security and lowest in people primed with avoidance. Conversely, we expected personal distress to be highest in people primed with attachment anxiety and lowest in people primed with security (Hypothesis 3 ). We hypothesized that prejudice (Hypothesis 4) and SDO (Hypothesis 5) would be highest in people primed with avoidance and lowest in people primed with security. Finally, we expected empathy to mediate the relationship between primed attachment and prejudice (Hypothesis 6); and primed attachment and SDO (Hypothesis 7). Specifically, we expected attachment security (versus avoidance) to be negatively associated with prejudice (and SDO) due to its positive association with empathy.

\section{Method}

\section{Participants}

Participants were 88 volunteers (92\% students, $83 \%$ female, $M_{\text {age }}=23.9, S D=$ 8.8) recruited from websites used in Study 1. Most participants were White (68.2\%), 20.4\% Black, 2.2\% mixedrace,3.4\% ChineseorAsian, 3.4\% 'anyotherethnic group', and $2.3 \%$ did not report ethnicity. The majority were Christian (50\%), 39.8\% identified themselves as 
not religious, $1.1 \%$ Buddhist, $1.1 \%$ Jewish, $1.1 \%$ Mormon, and $6.8 \%$ other. One participant was Muslim and was excluded.

Priming

The priming manipulations involved visualizing and writing about a specific type of relationship for 8 min (adapted from Bartz \& Lydon, 2004). The computer let the participant know when $8 \mathrm{~min}$ were up and then moved onto the next screen. For the secure prime, participants visualized a relationship involving emotional closeness, comfort in dependency on partner, and no fear of abandonment. For the avoidant prime participants visualized a relationship involving discomfort with closeness, difficulty depending on partner, and discomfort with partners' need for intimacy. For the anxious prime, participants visualized a relationship involving fear of abandonment or rejection from partner, and a desire for greater intimacy. In the secure condition, 15 participants wrote about a current romantic partner, five about a best friend/friend, four about an exromantic partner, and two about a sister. In the avoidant condition, eight participants wrote about a current romantic partner, five about a best friend/friend, 15 about an ex-romantic partner, two about a work/school colleague, and one about a dad ( 1 did not specify). In the anxious condition, nine participants wrote about a current romantic partner, three about a best friend/friend, and 16 about an ex-romantic partner (1 did not specify).

\section{Measures}

\section{Empathy}

Just as we would expect people who are high in dispositional empathy to be lessprejudiced, we thought that people who are empathic to one target (e.g., empathicresponses to Sam) would be less prejudiced to a different target (e.g., Muslims). In Study 2, the empathy and prejudice measures did not focus on the same target to reduce thechance of simply measuring a generalized positive attitude towards the target group withboth measures; this is a strength of our research. Index

We assessed empathy with a 12-item version of the Interpersonal Reactivity

(Davis, 1980; a = .85). Participants read a short first-person account about 'Sam' who expressed distress about a potential failure to meet a work deadline due to bothprocrastination and an increased workload due to an ill colleague. Items were modified toassess empathy towards Sam. Participants rated items on a 7-point scale ranging from 1

(not at all true) to 7 (extremely true). Four items assessed perspective taking ('I am able to understand Sam better by imagining how things look from Sam's perspective'; $a=$ .88 ), four items assessed empathic concern ('When I read of how Sam is feeling, I feel kind of protective towards Sam'; $a=.75)$, and four items assessed personal distress ('I feel helpless when I think of Sam's situation'; $a=.75$ ).

\section{Prejudice towards Muslims}

Prejudice was measured using a modified version of the 17-item Allophilia scale (Pittinsky, Rosenthal, \& Montoya, 2011a; a = .95). Participants rated agreement on a 6-point scale ranging from 1 (strongly disagree) to 6 (strongly agree); sample item: 'In general, Ihave positive attitudes about Muslims'. Although designed to measure positive attitudes 
towards outgroups, allophilia consistently negatively correlates with traditional measures of negative attitudes or prejudice (Henry \& Sears, 2002; McConahay, 1986), including blatant prejudice ( $r=-.82$; Pettigrew \& Merteens, 1995). Scores were reversed so that high scores indicate high prejudice. We modified the target group from African Americans to Muslims. The allophilia measure had five subscales (affection, comfort, kinship, engagement, and enthusiasm) that were highly correlated and combined.

\section{Social Dominance Orientation}

We used Pratto et al.'s (1994) 16-item SDO scale $(\mathrm{a}=.95)$. Participants rated agreement on a 6-point scale ranging from 1 (strongly disagree) to 6 (strongly agree). Eight items assessed social dominance ('If certain groups stayed in their place, we would have fewer problems') and eight items assessed social equality ('We would have fewer problems if we

treated people more equally'). Social equality items were reverse-scored and averaged with social dominance items.

\section{Procedure}

Participants completed materials online. To hide the purpose of the study our cover story stated we were exploring attention and the processing of written text. Participants were randomly assigned to either the secure, anxious, or avoidant attachment prime condition and then completed measures of empathy, prejudice and SDO; prejudice and SDO were counterbalanced. After measures were collected, to counteract any possible negative affect from the insecure primes, participants were asked to think of the five best things in their life, then thanked and debriefed.

Results

\section{Effectsofattachmentprimeonempathy}

A one-way Analysis of Variance (ANOVA) was computed on the dependent variables by prime (secure, anxiety, or avoidance; Table 2). Post hoc pairwise comparisons (Scheffe) were conducted. Consistent with Hypotheses 1 and 2, participants in the secure prime

Table 2. Empathy, prejudice, and social dominance orientation by primed attachment pattern (Study 2)

\begin{tabular}{|c|c|c|c|c|c|c|c|}
\hline & \multicolumn{6}{|c|}{ Primed attachment pattern } & \multirow[b]{3}{*}{$F$} \\
\hline & \multicolumn{2}{|c|}{ Secure } & \multicolumn{2}{|c|}{ Avoidant } & \multicolumn{2}{|c|}{ Anxious } & \\
\hline & M & $S D$ & $M$ & $S D$ & M & $S D$ & \\
\hline Perspective taking & $5.19 \mathrm{a}$ & 0.67 & $2.25_{b}$ & 1.23 & $4.43_{c}$ & 0.92 & $72.67 * * *$ \\
\hline Empathic concern & $4.62 \mathrm{a}$ & 0.99 & $2.0 \mathrm{I}_{\mathrm{b}}$ & 1.03 & $3.83_{c}$ & 0.75 & $61.17^{* * *}$ \\
\hline Personal distress & $2.1 \mathrm{I}_{\mathrm{a}}$ & 0.90 & $2.15_{a}$ & 0.82 & $4.36_{b}$ & 1.14 & $52.24 * * *$ \\
\hline Prejudice & $3.55_{a}$ & 1.01 & $4.69 \mathrm{~b}$ & 0.95 & $3.67 \mathrm{a}$ & 1.12 & $11.29 * * *$ \\
\hline Social Dominance Orientation & $2.22_{a}$ & 0.92 & $3.93_{b}$ & 1.24 & $2.50_{a}$ & 0.85 & $24.28 * * *$ \\
\hline
\end{tabular}

Note. Row means with different subscripts significantly differ at $p<.0$ I. Secure prime $N=27$, Avoidant prime $N=32$, Anxious prime $N=29$.

$* * * p<.001$. 
condition reported higher perspective taking and empathic concern than those in the avoidance or anxious prime conditions; furthermore, anxious-primed individuals reported higher perspective taking and empathic concern than did avoidant-primed individuals. Moreover, participants in the anxious prime condition reported higher personal distress than those in the secure or avoidant prime conditions, supporting Hypothesis 3.

\section{Effectsofattachmentprimeonprejudice}

Results (Table 2) showed that participants primed with security or anxiety reported lower prejudice towards Muslims and SDO than those primed with avoidance, consistent with Hypotheses 4 and 5. However, there were no differences between those primed with anxiety or security on prejudice or SDO.

\section{Correlation and mediation analyses}

Correlations (Table 3) showed that empathy was negatively associated with prejudiceand SDO. ${ }^{4}$ To examine whether the effect of attachment prime on prejudice (or SDO) wasmediated by any of the individual empathy subscales (perspective taking, empathicconcern, or personal distress), we used bootstrapping $(1,000$ resamples) for multiplemediators (Preacher \& Hayes, 2008). In analyses, we entered the three subscalessimultaneously to examine the unique indirect effect through each one. This proceduretests for differences in the relative sizes of the specific indirect effects (Hayes, 2009). A confidence interval for each contrast that does not include zero suggests that one indirecteffect is significantly larger than the other. Prime conditions were dummy coded so thatthe first dummy variable was coded 1 for avoidant prime and 0 for anxious or secure prime (hereincalled 'primed avoidance'), and the second dummy variable was coded 1 for anxiety prime and 0 for avoidant or security prime (herein called 'primed anxiety'). Primed security is the reference group.

Figure 1 shows the unstandardized coefficients and confidence intervals for the multiple mediation model for prejudice. The total effect of primed avoidance on prejudice was significant, but the direct effect was not. When taken as a set, the empathy subscales mediated the effect of primed avoidance on prejudice (the total indirect effect of empathy on prejudice through these variables was significant). However, examination of the specific indirect effects revealed that only empathic concern was significant. Contrasts showed a significant difference between empathic concern and personal distress. Therefore empathic concern uniquely explains the link between primed avoidance (vs. security) and prejudice above and beyond the effects of the other empathy subscales. Primed anxiety was not a significant predictor of prejudice.

Primed avoidance predicted high levels of SDO (Total effect of primed avoidance on SDO was significant: $1.71, p<.0001$, but the direct effect was not significant: $0.63, p=.14$ ). When all three empathy subscales were entered as a set of mediators no singleempathy subscale significantly predicted SDO, but the total indirect effect was significant, Total $R^{2}=.44, F(5,82)=12.95, p<.01(95 \% \mathrm{CI}=$ $0.16,1.72)$. Contrasts between the empathy subscales were not significant. This indicates that the significant mediating 
Table 3. Correlations between variables (Study 2)

\begin{tabular}{|c|c|c|c|c|c|c|c|c|}
\hline & I & 2 & & 3 & & 4 & 5 & 6 \\
\hline I. Empathy & - & & $.91 * *$ & & $.88 * *$ & $.51 * *$ & $-.53 * *$ & $-.64 * *$ \\
\hline 2. PT & & - & & & $.84^{* *}$ & .17 & $-.46 * *$ & $-.61^{* *}$ \\
\hline $\begin{array}{l}\text { 3. } E C \\
\text { 4. } P D\end{array}$ & & & & - & & $\begin{array}{l}.17 \\
-\end{array}$ & $\begin{array}{l}-.55^{* *} \\
-.22^{*}\end{array}$ & $\begin{array}{l}-.61 * * \\
-.24 *\end{array}$ \\
\hline 5. Prejudice & & & & & & & - & $.66 * *$ \\
\hline 6. SDO & & & & & & & & - \\
\hline
\end{tabular}

Note. $\mathrm{PT}=$ perspective taking ability; $\mathrm{EC}=$ empathic concern; $\mathrm{PD}=$ personal distress; $\mathrm{SDO}=$ Social Dominance Orientation.

$* p<.05 ; * * p<.01$.

effects of empathy on the link between primed avoidance on SDO are reliant on theinfluence of all empathy subscales. Similar to the results for prejudice, primed anxiety wasnot a significant predictor of SDO. ${ }^{5}$

\section{GENERAL DISCUSSION}

The aim of the current research was to examine the novel hypothesis that empathy is a mechanism through which the relationship between attachment patterns and prejudice can be explained. We demonstrate that congruent with previous research, primed attachment patterns consistently predict empathy (Joireman et al., 2001) and prejudice (Mikulincer \& Shaver, 2001). More importantly, we show that attachment security is linked tolow prejudice due to high empathy (Studies 1-2), and specifically, in comparison to attachment avoidance, due to high levels of empathic concern for others (Study 2). However, this latter interpretation is made with caution as empathic concern and perspective taking were highly correlated which might disguise the importance of perspective taking in this mediating role. It is important to contemplate why empathy plays a core role in the relationship between attachment patterns and prejudice by considering characteristics associated with attachment patterns.

Secure individuals learn empathic skills through the sensitive care they received from attachment figures; their parents' mind-mindedness facilitates their development of theory of mind (Meins et al., 2002), a necessary precursor to empathy. Furthermore, parents' reflective functioning allows them to teach their children to consider other' intentions and develop understanding for others (Fonagy et al., 1995). For example, in adulthood, secure individuals are responsive to others' self-disclosure (Mikulincer \& Nachshon, 1991), are socially competent (Zimmerman, 2004), hold positive views towards humanity (Luke et al., 2004), and appraise social situations as opportunities to foster closeness and personal growth (Feeney, Cassidy, \& Ramos-Marouse, 2008), characteristics opposing prejudice. Indeed low prejudiced individuals develop friend- 


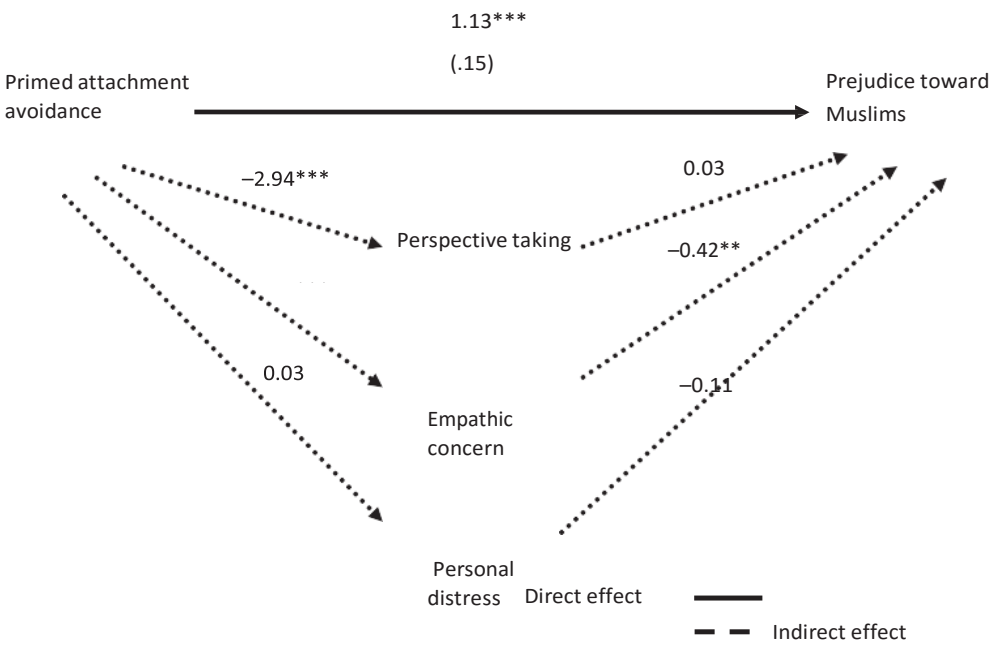

Model Summary: $R^{2}=.33, F(5,82)=7.90, p<.001$

95\% CI: Perspective Taking $(-1.00,0.81)$

95\% CI: Total Indirect Effect $(0.11,1.74)^{*}$ 95\% CI: Empathic Concern $(0.29,1.81)^{*}$

95\% CI: Personal Distress $(-0.12,0.05)$

95\% Contrast CI: Empathic Concern versus. Personal Distress $(0.30,1.84)^{*}$

95\% Contrast CI: Empathic Concern versus. Perspective Taking $(-2.62,0.33)$

$95 \%$ Contrast CI: Perspective Taking versus. Personal Distress $(-1.03,0.83)$

Figure 1. Unstandardized coefficients demonstrating the mediating effect of empathy subscales on relationship between primed attachment avoidance and prejudice (Study 2).

Note. Total effect $=1.13^{* * *}$; Direct effect $=0.15 .{ }^{* * *} p<.001 ; * * p<.01 ; * p<.05$.

ships with outgroup members (Pettigrew, 1997). Although it is possible that the effects ofprimed security are due to positive mood, this explanation is unlikely as Mikulincer andShaver (2001) found that security priming led to less prejudice than a neutral prime whenmood was statistically controlled and that security priming led to less prejudice than did apositive-affect prime. Finally, Mikulincer et al. (2001) found that primed security lead to more empathy than did a positive-affect prime or a neutral prime, and these effects werenot due to mood.

The attachment history of those high in attachment anxiety involves having inconsistent, intermittent care that encourages them to display negative affect in order to get their attachment needs met. They learn that affective displays will eventually be responded to (Crittenden, 1997) and thus may attend to distress in others and reflect it back. However, feeling distressed when others are upset is not the same as understanding another's thoughts and feelings, rather it is selffocused. Perhaps this is why high personal distress has no mediating role in the relation between attachment anxiety and prejudice. Feeling personal distress at another's plight is an aversive feeling that does not appear to make attachmentanxious individuals focus outwards and show tolerance for outgroups.

Inconsistent with previous research that found dispositional attachment anxiety to be related to more prejudice (Di Pentima \& Toni, 2009; Mikulincer

$\&$ Shaver, 2001), we found no difference between those primed with anxiety versus security in reported prejudice.

The attachment history of a highly avoidant person which lacks parental mind- mindedness and reflective functioning, and augments self-directed responding as a means 
of increasing self-reliance and independence, does not lead to the acquisition of empathicconcern. In turn, their lack of empathic concern amplifies intolerance towards othersleading to increased prejudice. Avoidant individuals have low humanity-esteem (Luke et al., 2004), and when under threat perceive others as different from themselves(Mikulincer, Orbach, \& Iavnieli, 1998); indeed, research shows that people high(compared to low) in prejudice rate outgroup members as less similar to themselves(Graziano, Bruce, Tobin, \& Sheese, 2007).

One might argue that highly avoidant individuals are not merely prejudiced towards certain groups, but are misanthropic. Blom, van Middendorp, and Geenen (2012) foundthat high scores on preoccupied and fearful attachment were associated positively withmisanthropy, whereas dismissing-avoidance was unrelated to misanthropy and secureattachment was negatively associated with misanthropy, suggesting our findings may notbe due to avoidant individuals hating everyone.

\section{Implications and future directions}

The advantage of priming attachment patterns is it allows one to examine causal processes. By activating a given attachment style, via spreading activation across schemasan individual can bring to mind other thoughts and feelings associated with the primedschema which cause the individual to act in accordance with that attachment style (albeittemporarily). Research shows (Carnelley, Otway, \& Rowe, 2015; Carnelley \& Rowe, 2007) that with repeated priming of attachment security, participants report morepositive self-views and relationship expectations 2 days after the last prime, and more feltsecurity and less anxious mood 1 day after the final prime. This suggests that repeatedsecurity priming might be used in an intervention to increase empathy and reduceprejudice.

Given the high correspondence in caregiver-offspring attachment patterns (Benoit \& Parker, 1994; Main, Kaplan, \& Cassidy, 1985), and that the parenting practices of one generation are largely consistent with those of subsequent generations (Chen \& Kaplan, 2001; van IJzendoorn, 1992), decreasing the prevalence of insecure attach- ment patterns requires early intervention. Future research should inform and test interventions that encourage parents to adopt reflective functioning and mind- mindedness in their relationships with their infants (Baradon, Fonagy, Bland, Lenard, \& Sleede, 2008). This in turn should lead to their infants developing positive internal working models and learning vital empathic skills. The ability and motivation to consider the thoughts and feelings of another person should facilitate the development of positive views of outgroup members thus reduce ingroup-bias, and increase intergroup contact.

It is unclear whether intergroup contact will decrease prejudice for highly avoidant people. On the one hand, they may be less likely to benefit from intergroup contactsituations because of their physical and psychological distancing. On the other hand,research illustrates that dismissing-avoidant individuals are less likely to identify with ingroups than fearful-avoidant individuals. This suggests that dismissing individuals may show less ingroup-bias, which may facilitate intergroup contact leading to reducedprejudice (Crisp et al., 2009).

Nevertheless, our results suggest that one possible way of reducing prejudice in highly avoidant individuals is to train them to develop empathic skills, such as perspective taking.Future research should consider whether manipulating empathic concern or perspectivetaking will decrease prejudicial responding in people primed with attachment avoidance. 
By testing the role of empathic concern experimentally, it would be possible to identifywhether it is the fundamental component needed in prejudice reduction techniques.Additionally, future research might investigate the effectiveness of priming security andteaching perspective taking on reducing prejudice for those high in dispositionalavoidance. Does primed security increase the motivation to learn empathic skills such as perspective taking, or increase empathic concern for those who are dispositionallyavoidant?

A strength of the present research is that the assessment of empathy was not measured with regard to the target of prejudice, therefore not confounding the empathy and prejudice measures. This suggests that empathy training need not necessarily focus on marginalized groups to successfully reduce prejudice.

Our research is not without limitations. Participants were mostly white female students in their early 20 s, thus we cannot assume that our findings are representativeof a sample with more life experience or stronger political/social group affiliationrelated to prejudicial responding. However, in a less liberal sample we would expectthe pattern of results to replicate, albeit with greater variance in prejudice and SDO.One might argue that a limitation was the use of internet-based data collection. However, research demonstrates that experimental results collected in the lab areconsistent with those collected online (Birnbaum, 2001), suggesting the findings arevalid. Furthermore, we monitored the amount of time participants spent on the primetask and inspected the prime task text to ensure participants were engaged with thetask. Some correlations between our self-report variables were high, which may indicatecommon method variance; however, Harman single-factor analyses suggested that thiswas not problematic. Nevertheless, future research should use different methods, suchas close others' reports on participants' empathic skills or observation of discrimination. Boag and Carnelley (2012) found that those primed with security engage in less discriminatory behaviour against Muslims, consistent with our findings for prejudice. Inboth studies we did not measure dispositional attachment style and were unable toexamine whether the security prime was equally beneficial for people with differinglevels of attachment anxiety and avoidance, an avenue for future research. Finally, givenour findings are similar across studies that use measures with and without mid-points, we can be fairly confident that we have not forced participants to appear moreprejudiced or less empathic than they actually are by including measures that have nomid-point.

\section{Summary andconclusions}

In two studies, we show that attachment relates to prejudice through the mechanism of empathy. We find that primed attachment security is negatively associated with prejudice due to high empathy. Moreover, we show that empathic concern explains the attachment security (versus avoidance) differences in prejudice towards Muslims. Although by no means a panacea, interventions might examine ways to increase attachment security and empathy in order to blow away 'the dark clouds of prejudice' of which King (1963) spoke.

\section{Acknowledgements}

We would like to thank Constantine Sedikides and Erica Hepper for their invaluable advice during the preparation of this manuscript. 



\section{References}

Ainsworth, M. D. S., Blehar, M. C., Waters, E., \& Wall, S. (1978). Patterns of attachment: Assessed in the strange situation and at home. Hillsdale, $\mathrm{NJ}$ : Erlbaum.

Akrami, N., Ekehammar, B., \& Araya, T. (2000). Classical and modern racial prejudice: A study of attitudes toward immigrants in Sweden. European Journal of Social Psychology, 30, 521-532. doi:10.1002/1099-0992(2000007/08)30:4<521:AID EJSP5>3.0.CO:2-N

Allport, G. W. (1954/1979). The nature of prejudice. Cambridge, MA: Perseus Books.

B€ackstro€m, M., \& Bjo€rkund, F. (2007). Structural modeling of generalized prejudice: The role of social dominance, authoritarianism, and empathy. Journal of Individual Differences, 28, 10-17. doi:10.1027/1614-0001.28.1.10

Baldwin, M. W., Keelan, J. P. R., Fehr, B., Enns, V., \& Koh-Rangarajoo, E. (1996). Social cognitive conceptualization of attachment working models: Availability and accessibility effects. Journal of Personality and Social Psychology, 71, 94-109. doi:10.1037/00223514.71.1.94

Baradon, T., Fonagy, P., Bland, K., Lenard, K., \& Sleede, M. (2008). New beginnings -An experience- based programme addressing the attachment relationship between mothers and their babies in prisons. Journal of Child Psychotherapy, 34, 240-258. doi:1080/00754170802208065

Baron-Cohen, S. (2001). Theory of mind in normal development and autism. Prisme, 34, 174183. Retrievedfrom http://autism.bibliomaker.ch/BM_DIRECTORY/I/BM000001204/7250/BAR16.PDF

Baron-Cohen, S., \& Wheelwright, S. (2004). The empathy quotient: An investigation of adults with Asperger syndrome or high functioning autism, and normal sex differences. Journal of Autism and Developmental Disorders, 34, 163-175. doi:10.1023/B:JADD.0000022607. 19833.00

Bartholomew, K., \& Horowitz, L. M. (1991). Attachment styles among young adults: A test of a four- category model. Journal of Personality and Social Psychology, 61, 226-244.

Bartz, J. A., \& Lydon, J. E. (2004). Close relationships and the working self-concept: Implicit and

explicit effects of priming attachment on agency and communion. Personality and Social Psychology Bulletin, 30, 1389-1401.doi:10.1177/0146167204264245

Batson, C. D. (1991). The altruism question: Toward a social-psychological answer. Hillsdale, NJ: Erlbaum.

Batson, C. D., \& Ahmad, N. Y. (2009). Using empathy to improve intergroup attitudes and relations. Social Issues and Policy Review, 3, 141-177.doi:10.1111/j.1751-24092009.01013.x

Batson, C. D., Chang, J., Orr, R., \& Rowland, J. (2002). Empathy, attitudes, and action: Can feeling for a member of a stigmatized group motivate one to help the group? Personality and Social Psychology Bulletin, 28, 1656-1666. doi: $10.1177 / 014616702237647$

Batson, C. D., Eklund, J.H., Chermok, V.L., Hoyt, J. L., \& Ortiz, B. G. (2007). An additional antecedent

of empathic concern: Valuing the welfare of the person in need. Journal of Personality and Social Psychology, 93, 65-74. doi:10.1037/0022-3514.93.1.65

Batson, C. D., Polycarpou, M. P., Harmon-Jones, E., Imhoff, H. J., Mitchener, E. C., Bednar, L. L., ... Highberger, L. (1997). Empathy and attitudes: Can feeling for a member of a stigmatized group improve feelings toward the group? Journal of Personality and Social Psychology, 72, 105-118. doi:10.1037/0022-3514.72.1.105

Benoit, D., \& Parker, K. (1994). Stability and transmission of attachment across three generations. Child Development, 65, 1444-1456. doi:10.111/j.1467-8624.1994.tb00828.x

Birnbaum, M. H. (2001). Introduction to behavioral research on the internet. Upper Saddle River,NJ: Prentice Hall.

Blom, D., van Middendorp, H., \& Geenen, R. (2012). Anxious attachment may be a vulnerability factor for developing embitterment. Psychology and Psychotherapy: Theory, Research and Practice, 85, 351-355.doi:10.1111/j.2044-8341.2011.02039.x

Boag, E., \& Carnelley, K. B. (2012). Self-reported discrimination and discriminatory behaviour: The role of attachment security. British Journal of Social Psychology, 51, 393-403. doi:10.1111/ j.2044-8309.2011.02065.x

Bowlby, J. (1969). Attachment and loss (Vol. 1): Attachment. London, UK: Pimlico. 
Britton, P. C., \& Fuendeling, J. M. (2005). The relations among varieties of adult attachment and the components of empathy. The Journal of Social Psychology, 145, 519-530. doi:10.3200/ SOCP.145.5.519-530

Carnelley, K. B., Otway, L., \& Rowe, A. C. (2015). The effects of attachment priming on depressed and anxious mood. Clinical Psychological Science. Advance online publication. doi:10.1177/ 2167702615594998

Carnelley, K. B., \& Rowe, A. C. (2007). Repeated priming of attachment security influences immediate and later views of self and relationships. Personal Relationships, 14, 307-320.

Carnelley, K. B., \& Story, A. L. (2008, February). Adult attachment and appetitive and aversive goals. Poster presented at the 9th Annual Meeting of the Society for Personality and Social Psychology, Albuquerque, NM.

Chen, Z. Y., \& Kaplan, H. B. (2001). Intergenerational transmission of constructive parenting. Journal of Marriage and Family, 63, 17-31. doi:10.1111/j.17413737.2001.00017.x

Collins, N. L., Ford, M., Guichard, A., Kane, H. S., \& Feeney, B. C. (2009). Responding to need in intimate relationships: Social support and caregiving processes in couples. In M. Mikulincer \& P. R. Shaver (Eds.), Prosocial motives, emotions, and behavior (pp. 367388). Washington, DC: American Psychological Association.

Collins, N. L., \& Read, S. J. (1994). Cognitive representations of attachment: The content and function of working models. In K. Bartholomew \& D. Perlman (Eds.), Advances in personal relationships (Vol. 5, pp. 53-90). London, UK: Kingsley.

Cotterell, C. A., \& Neuberg, S. L. (2005). Different emotional reactions to different groups: Asociofunctional threat-based approach to 'prejudice'. Journal of Personality and Social Psychology, 88, 770-789. doi:10.1037/0022-3514.88.5.770

Crisp, R. J., Farrow, C. V., Rosenthal, H. E. S., Walsh, J., Blissett, J., \& Penn, N. M. K. (2009). Interpersonal attachment predicts identification with groups. Journal of Experimental Social Psychology, 45, 115-122.doi:10.1016/j.jesp.2008.09.006

Crittenden, P. M. (1997). The effect of early relationship experiences on relationships in adulthood. In S. Duck (Ed.), Handbook of personal relationships: Theory, research and interventions (pp. 99-119). Chichester, UK: John Wiley.

Davis, M. H. (1980). A multidimensional approach to individual differences in empathy. JSAS Catalog of Selected Documents in Psychology, 10, 85. Retrieved from http://www.uv.es/ friasnow/Davis_1980.pdf

Di Pentima, L., \& Toni, A. (2009). Subtle, blatant prejudice and attachment: A study in adolescent age. Giornale de Psicologia, 3, 153-163. Retrieved from http://giornaledispsicologia.it/gdp/ gdp.2009.2/GiornaleDiPsicologia.2009.2.pdf

Feeney, B. C., Cassidy, J., \& Ramos-Marouse, F. (2008). The generalisation of attachment representations to new social situations: Predicting behavior during initial interaction with strangers. Journal of Personality and Social Psychology, 95, 1481-1498. doi:10.1037/ a0012635

Feeney, B. C., \& Collins, N. L. (2001). Predictors of caregiving in adult intimate relationships: An attachment theoretical perspective. Journal of Personality and Social Psychology, 80, 972-994.

Finlay, K. A., \& Stephan, W. G. (2000). Improving intergroup relations: The effects of empathy on racial attitudes. Journal of Applied Social Psychology, 30, 1720-1737. doi:10.1111/j.1559- 1816.2000.tb02464.x

Fonagy, P., Redfern, S., \& Charman, T. (1997). The relationship between belief-desire reasoning and a projective measure of attachment security SAT. British Journal of Developmental Psychology, 15, 1-61. doi:10.1111/j.2044-835X.1997.tb00724.x

Fonagy, P., Steele, M., Steele, H., Leigh, T., Kennedy, R., Mattoon, G., \& Target, M. (1995). Attachment, the reflective self, and borderline states: The predictive specificity of the Adult Attachment Interview and pathological emotional development. In S. Goldberg, R. Muir \& J. Kerr (Eds.), Attachment theory: Social, developmental and clinical perspectives (pp. 233-278). New York, NY: Analytic Press. 
Gable, S. L. (2006). Approach and avoidance social motives and goals. Journal of Personality, 74, 175-222. doi:10.111/j.1467-6494.2005.00373.x

Galinsky, A. D., \& Moskowitz, G. B. (2000). Perspective taking: Decreasing stereotype expression, stereotype accessibility and in-group favoritism. Journal of Personality and Social Psychology, 78, 708-724. doi:10.1037/0022-3514.78.4.708

Graziano, W. G., Bruce, J., Tobin, R. M., \& Sheese, B. E. (2007). Attraction, personality, and prejudice: Liking none of the people most of the time. Journal of Personality and Social Psychology, 93, 565-582. doi:10.1037/0022-3514.93.3.565

Hamilton, C. E. (2000). Continuity and discontinuity of attachment from infancy through adolescence. Child Development, 71, 690-694. doi:10.1111/1467-8624.00177

Hayes, A. F. (2009). Beyond Baron and Kenny: Statistical mediation analysis in the new millennium. Communication Monographs, 76, 408-420. doi:10.1080/03637750903310360

Henry, P. J., \& Sears, D. O. (2002). The Symbolic Racism 2000 Scale. Political Psychology, 23, 253-283. doi:10.1111/0162-895X.00281

Hofstra, J., van Oudenhoven, J.P., \& Buunk, B.P.(2005). Attachment styles and majority members attitudes towards adaptation strategies of immigrants. International Journal of Intercultural Relations, 29, 601-619. doi:10.1016/j.ijintrel.2005.05.009

Joireman, J. A., Needham, T., \& Cummings, A. (2001). Relationships between dimensions of attachment and empathy. North American Journal of Psychology, 4, 63-80. Retrieved from http://eric.ed.gov/PDFS/ED473748.pdf

King, M. L. Jr (1963). Letter from a Birmingham jail. Retrieved from http://www.oaktree.us/stuff/ King-Birmingham.pdf

Kumashiro, M., \& Sedikides, C. (2005). Taking on board liability-focused feedback: Close positive relationships as a self-bolstering resource. Psychological Science, 16, 732-739. doi:10.1111/ j.1467-9280.2005.01603.x

Luke, M. A., Maio, G. R., \& Carnelley, K. B. (2004). Attachment models of the self and others: Relations with self-esteem, humanity-esteem, and parental treatment. Personal Relationships, 11, 281-303. doi:10.1111/j.1475-6811.2004.00083.x

Luke, M. A., Sedikides, C., \& Carnelley, K. (2012). Your love lifts me higher! The energizing quality of secure relationships. Personality and Social Psychology Bulletin, 38, 721-733. doi:10.1177/ 0146167211436117

Main, M. (1990). Cross-cultural studies of attachment organization: Recent studies, changing methodologies, and the concept of conditional strategies. Human Development, 33, 48 61. doi:10.1159/000276502

Main, M., Kaplan, N., \& Cassidy, J. (1985). Security in infancy, childhood, and adulthood: A move to the level of representation. Monographs of the Society for Research in Child Development, 50,66-104.

McConahay, J. B. (1986). Modern racism, ambivalence, and the Modern Racism Scale. In J. F.

Dovidio \& S. L. Gaertner (Eds.), Prejudice, discrimination, and racism (pp. 91-125). Orlando, FL:Academic Press.

Mehrabian, A., \& Epstein, N. (1972). A measure of emotional empathy. Journal of Personality, 40, 525-543. doi:10.1111/j.1467-6494.1972.tb00078.x

Meins, E., Fernyhough, C., Russell, J., \& Clark-Carter, D. (1998). Security of attachment as a predictor of symbolic and mentalising abilities: A longitudinal study. Social Development, 7, 1-24. doi:10.1111/1467-9507.00047

Meins, E., Fernyhough, C., Wainwright, R., Das Gupta, M., Fradley, E., \& Tuckey, M. (2002). Maternal mind-mindedness and attachment security as predictors of theory of mind understanding. Child Development, 73, 1715-1726. doi:10.1111/j.1467-8624.00501

Menard, S. (1995). Applied logistic regression analysis. Quantitative Applications in the Social Sciences (pp.106). London, UK: Sage.

Meyer, B., Olivier, L., \& Roth, D. A. (2005). Please don't leave me! BIS/BAS, attachment styles, and responses to a relationship threat. Personality and Individual Differences, 38, 151-162. doi:10.1016/j.paid.2004.03.016 
Mikulincer, M. (1997). Adult attachment style and information processing: Individual differences in curiosity and cognitive closure. Journal of Personality and Social Psychology, 72, 1217-1230. doi:10.1037/0022-3514.72.5.1217

Mikulincer, M., Orbach, I., \& Ivanieli, D. (1998). Adult attachment style and affect regulation: Strategic variations in subjective self-other similarity. Journal of Personality \& Social Psychology, 75, 436-448. doi:10.1037/0022-3514.75.2.436

Mikulincer, M., Gillath, O., Halevy, V., Avihou, N., Avidan, S., \& Eshkoli, N. (2001). Attachment theory and reactions to others' needs: Evidence that activation of the sense of attachment security promotes empathic responses. Journal of Personality and Social Psychology, 81, 1205-1224. doi:10.1037/0022-3514.81.6.1205

Mikulincer, M., \& Nachshon, O. (1991). Attachment styles and patterns of self-disclosure. Journal of Personality and Social Psychology, 61,321-331. doi:10.1037/00223514.61.2.321

Mikulincer, M., \& Shaver, P. R. (2001). Attachment theory and intergroup bias: Evidence that priming the secure base schema attenuates negative reactions to out-groups. Journal of Personality and Social Psychology, 81, 97-115. doi:10.1037/0022-3514.81.1.97

Mikulincer, M., \& Shaver, P. R. (2007). Attachment in adulthood: Structure, dynamics, and change. New York, NY: Guilford Press.

Mikulincer, M., Shaver, P. R., Gillath, O., \& Nitzberg, R. E. (2005). Attachment, caregiving, and altruism: Augmentation of attachment security increases compassion and helping. Journal of Personality and Social Psychology, 85, 817-839. doi:10.1037/00223514.89.5.817

Mikulincer, M., Shaver, P. R., Sahdra, B. K., \& Bar-On, N. (2013). Can securityenhancing interventions overcome psychological barriers to responsiveness in couple relationships? Attachment and Human Development, 15, 246-260. doi:10.1080/14616734.2013.782653

Noftle, E. E., \& Shaver, P. R. (2006). Attachment dimensions and the Big Five personality traits: Associations and comparative ability to predict relationship quality. Journal of Research in Personality, 40, 179-208. doi:10.1016/j.jrp.2004.11.003

Pederson, A., Beven, J., Walker, I., \& Griffiths, B. (2004). Attitudes toward indigenousAustralians: The role of empathy and guilt. Journal of Community and Applied Social Psychology, 14, 233-249. doi:10.1002/casp.771

Pettigrew, T. F. (1997). Generalised intergroup contact effects on prejudice. Personality and SocialPsychology Bulletin, 23, 173-185. doi:10.1177/0146167297232006

Pettigrew, T. F., \& Merteens, R. W. (1995). Subtle and blatant prejudice in western Europe. European Journal of Social Psychology, 25, 57-75. doi:10.1002/ejsp.2420250106

Pettigrew, T. F., \& Tropp, L. R. (2008). How does intergroup contact reduce prejudice? Metaanalytictests of three mediators. European Journal of Social Psychology, 38, 922-934. doi:10.1002/ ejsp.504

Pittinsky, T. L., Rosenthal, S. A., \& Montoya, R. M. (2011a). Measuring positive attitudes toward outgroups: Development and validation of the Allophilia scale. In L. Tropp \& R. Mallett (Eds.), Beyond prejudice reduction: Pathways to positive intergroup relations. Washington, DC: American Psychological Association.

Pratto, F., Liu, J., Levin, S., Sidanius, J., Shih, M., Bachrach, H., \& Hegarty, P. (2000). Social dominance orientation and the legitimization of inequality across cultures. Journal of Cross-Cultural Psychology, 31, 369-409. doi:10.1177/0022022100031003005

Pratto, F., Sidanius, J., Stallworth, L. M., \& Malle, B. F. (1994). Social dominance orientation: Apersonality variable predicting social and political attitudes. Journal of Personality and Social Psychology, 67, 741-763. doi:10.1037/0022-3514.67.4.741

Preacher, K. J., \& Hayes, A. F. (2004). SPSS and SAS procedures for estimating indirect effects in simple mediation models. Behavior Research Methods, Instruments, and Computers, 36,717-731. Retrieved from http://brm.psychonomic-journals.org/content/36/4/717.full.pdf+ html

Preacher, K. J., \& Hayes, A. F. (2008). Asymptotic and resampling strategies for assessing and comparing indirect effects in multiple mediator models. Behavior Research Methods, 40, 879-891. doi:10.3758/BRM.40.3.879 
Rowe, A., \& Carnelley, K. B. (2003). Attachment style differences in the processing of attachment- relevant information: Primed-style effects on recall, interpersonal expectations, and affect. Personal Relationships, 10,59-75. doi:10.1111/14756811.00036

Rowe, A., \& Mohr, C. (2007). Empathy differs as a function of individuals' dispositional attachment style. Unpublished manuscript. Bristol, UK: University of Bristol.

Sidanius, J., Levin, S., Liu, J. H., \& Pratto, F. (2000). Social dominance orientation and the political psychology of gender: An extension and cross-cultural replication. European Journal of Social Psychology, 30, 41-67. doi:10.1002/(SICI)1099992(2000001/02)30:1<41:AID_EJSP976> 3.0.CO:2-0

Sidanius, J., \& Pratto, F. (1999). Social dominance: An intergroup theory of social hierarchy and oppression. New York, NY: Cambridge University Press.

Sroufe, L. A., \& Waters, E. (1977). Attachment as an organizational construct. Child Development, 48, 1184-1199. Retrieved from http://www.psychology.sunysb.edu/attachment/online/org_ construct.pdf

Trusty, J., Ng, K. M., \& Watts, R. E. (2005). Model of effects of adult attachment on emotional empathy of counseling students. Journal of Counseling and Development, 83, 66-77. Retrieved from http://aca.metapress.com/openurl.asp?genre=article\&eissn=1556$6676 \&$ volume $=83 \&$ issue $=1 \&$ spage $=66$

van IJzendoorn, M. H. (1992). Intergenerational transmission of parenting: A review of studies in non-clinical populations. Developmental Review, 12, 76-99. doi:10.1016/0273-2297(92) 900004-L

van Oudenhoven, J. P., \& Hofstra, J. (2006). Personal reactions to ‘strange' situations: Attachment styles and acculturation attitudes of immigrants and majority members. International Journal of Intercultural Relations, 30, 783-798. doi:10.1016/j.ijintrel.2006.05.005

Wayment, H. A. (2006). Attachment style, empathy, and helping following a collective loss: Evidence from the September 11th terrorist attacks. Attachment and Human Development, 8, 1-9. doi:10.1080/14616730600585292

Weber, C., \& Federico, C. A. (2007). Interpersonal attachment and patterns of ideological belief. Political Psychology, 28, 389-416. doi:10.1111/j.1467-9221.2007.00579.x

Zick, A., Ku€pper, B., \& Ho€vermann, A. (2011). Intolerance, prejudice and discrimination: A European report. Berlin, Germany: Friedrich-Ebert-Stiftung. Retrieved from: https://pub. uni-bielefeld.de/luur/download?func=downloadFile\&record OId $=2018626 \&$ fileOId $=2269239$

Zimmerman, P. (2004). Attachment representations and characteristics of friendship relationsduring adolescence. Journal of Experimental Child Psychology, 88, 83-101. doi:10.1016/ j.jecp.2004.02.002 